\title{
Evaluasi gambaran radiografi CBCT fraktur kepala kondilus pada anak
}

\author{
Merry Annisa Damayanti ${ }^{*}$, Azhari', Lusi Epsilawati ${ }^{1}$
}

ABSTRACT

Objectives: was to evaluate the radiographic of pain when opening the mouth and experiencing CBCT fractures in the neck of condyle

facial asymmetry. The CBCT radiograph shows a

Case Report: 11 years old boy was referred from the emergency department of RSGM UNPAD for $C B C T$ radiographic examination with a suspected clinical diagnosis of left condyle fracture. The patient had an accident falling while playing one day ago. The patient complained of pain in the left ear, fragment of the condyle head and has a medial displacement

Conclusion: CBCT can see the fragments' location in the fracture and changes in size and position direction that occur, whereas conventional

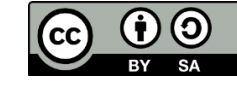

This work is licensed under a Creative Commons Attribution 4.0 which permits use, distribution and reproduction,
provided that the original work is properly cited, provided that the original work is properly cited,
the use is non-commercial and no modifications or adaptations are made.
and

${ }^{1}$ Departemen Radiologi Kedokteran Gigi, Fakultas Kedokteran Gigi, Universitas Padjadjaran, Bandung, Indonesia, 40132

${ }^{*}$ Correspondence to:

Merry Annisa Damayanti

هmerry.annisa@unpad.ac.id

Received on: October 2020 Revised on: November 2020 Accepted on: December 2020
Keywords: Condyle fracture, $C B C T$, plain radiograph

Cite this article: Damayanti A.M, Azhari, Epsilawati. Evaluasi gambaran radiografi CBCT fraktur kepala kondilus pada anak. Jurnal Radiologi Dentomaksilofasial Indonesia 2020;4(3)79-82. https://doi.org/10.32793/jrdi.v4i3.623

\section{PENDAHULUAN}

Kecelakaan lalu lintas sering menimbulkan keadaan superimpose yang sulit diatasi. cedera yang dapat membuat cacat tubuh. Setiap tahunnya angka kecelakaan yang disebabkan lalu lintas semakin meningkat. ${ }^{1,2}$ Kementrian Kesehatan Indonesia dan World Hearlth Organization (WHO), mencatat bahwa kecelakaan lalu lintas dapat menyebabkan kematian ataupun cedera pada anggota tubuh. ${ }^{3,4}$ Cedera pada tulang wajah merupakan cedera yang paling sering dijumpai dan menjadi salah satu penyebab utama kecacatan dan kematian pada manusia. Persentase fraktur tulang wajah yang paling sering terjadi pada fraktur tulang mandibular (61\%), fraktur pipi $(27 \%)$, dan fraktur hidung $(19,5 \%)$.

Tulang mandibula merupakan bagian yang sering mengalami trauma karena bentuk anatomis yang lebih menonjol dibandingkan dengan tulang wajah lainnya dan letaknya yang berada di bawah tulang wajah yang merupakan daerah yang pertama kali berdampak ketika jatuh. Anatom tulang mandibular yang paling sering terjadi fraktur yaitu daerah kondilus-subkondilus (29\%), angulus mandibular (24\%), simfisis parasimsifis (22\%). ${ }^{5,6}$

Untuk melihat kondisi fraktur, diperlukan alat bantu diagnosis, biasanya digunakan radiografi. Intraoral periapikal dan oklusal radiografi biasa digunkan untuk melihat kondisi frakur pada daerah gig ataupun intra oral baik maksila maupun madibula, sedangkan untuk lokasi fraktur yang lebih luas diperlukan radiografi elstra oral. Radiografi ekstraotral yang paming umum digunakan adakah panoramik radiograf. Akan tetapi tehnik ini banyak sekali kekurangannya terutama apabila bertemu dengan
Selain itu untuk fraktur terkadang diperlukan beberapa pandangan dari bernagai arah, shinnga diagnisa menjadi lengkap. ${ }^{7}$ Perlu perhatian khusus untuk melihat fraktur yang terjadi pada gambaran konvensional, radiografik karena beberapa kasus sulit dilihat hanya menggunakan radiografik konvensional. Radiografik CBCT dapat menampilkan gambaran 3D yang dapat menampilkan gambaran lokasi fraktur pada area condilus secara menyeluruh. Tujuan laporan kasus ini untuk mengevaluasi gambaran CBCT fraktur yang terjadi pada leher kondilus.

\section{LAPORAN KASUS}

Pasien anak laki-laki usia 11 tahun datang bersama orang tuanya dirujuk dari instalasi gawat darurat Rumah Sakit Gigi dan Mulut Universitas Padjadjaran untuk dilakukan pemeriksaan radiografi $\mathrm{CBCT}$ dengan suspek diagnosis klinis fraktur kondilus sinistra. Pasien mengalami kecelakan terjatuh saat bermain satu hari yang lalu. Pasien mengeluhkan sakit pada telinga kiri, sakit pada saat membuka mulut dan mengalami asimetris wajah. Pemeriksaan klinis menunjukkan wajah sebelah kiri mengalami pembengkakan di daerah sekitar telinga dan pipi serta pasien mengalami keterbatasan saat membuka mulut (Gambar 1). Kemudian pasien dilakukan pemeriksaan radiografi CBCT.

Hasil pemeriksaan CBCT menampilkan tampilan 
coronal, sagittal, dan axial kondilus sinistra (Gambar 2). Gambaran pandangan coronal kondilus sinistra menunjukkan fraktur pada leher kondilus (Gambar 3). Fragmen fraktur kepala kondilus mengalami displacement sebesar $\pm 1 \mathrm{~mm}-1,9 \mathrm{~mm}$ ke arah medial leher kondilus. Fragmen fraktur irregular dengan ukuran $\pm 9,0 \mathrm{~mm}$ (supero-inferior) $\mathrm{x} \pm 13,8$ $\mathrm{mm}$ (medio-lateral). Gambaran pandangan sagital kondilus sinistra menunjukkan fraktur pala leher kondilus dimana fragmen fraktur berada pada sisi medial leher kondilus (Gambar 4). Lebar anteroposterior leher kondilus $\pm 8,8 \mathrm{~mm}$. Jarak dari leher kondilus ke fossa eminensia $\pm 6,4 \mathrm{~mm}$. Posisi kondilus berada lebih anterior dari fossa glenoidalis dan terletak di fossa eminensia. Jarak dari kepala kondilus ke fossa eminensia $\pm 1 \mathrm{~mm}$. Gambaran pandangan axial kondilus sinistra menunjukkan fraktur pada kondilus dimana fragmen fraktur berada pada sisi medial dengan ukuran $\pm 5,1 \mathrm{~mm}$ (antero-posterior) $\mathrm{x} \pm 12,1 \mathrm{~mm}$ (medio-lateral) (Gambar 5).

Gambaran pandangan coronal, sagittal, dan axial kondilus dextra menunjukkan tidak terdapat kelainan (Gambar 6). Gambaran pandangan coronal kondilus dextra menunjukkan posisi kondilus dextra berada lebih ke anterior dari fossa glenoid (Gambar 7). Jarak dari kepala kondilus ke fossa glenoidalis \pm $4,1 \mathrm{~mm}$. Ukuran kepala kondilus $\pm 14,9 \mathrm{~mm}$ dan leher kondilus $\pm 7,8 \mathrm{~mm}$. Gambar Gambaran pandangan sagital kondilus dextra menunjukkan posisi kondilus dextra berada lebih ke anterior dar fossa glenoidalis mendekati fossa eminensia. Ukuran kepala kondilus $\pm 5,7 \mathrm{~mm}$ dan leher kondilus $\pm 4,5 \mathrm{~mm}$. Gambaran pandangan axia kondilus dextra menunjukkan ukuran kepala kondilus $\pm 4,2 \mathrm{~mm}$ (antero-posterior) $\mathrm{x} \pm 14 \mathrm{~mm}$ (medio-lateral). Gambaran tiga dimensi menunjukkan kondisi kondilus dextra dan sinistra (Gambar 8). Kesan dari kasus ini terdapat fraktur leher kondilus sinistra ke arah medial dan kondilus dextra berada lebih ke anterior dari fossa glenoid, sehingga dapat diambil kesimpulan radiodiagnosis fraktur leher kondilus sinistra dengan medial displacement kepala kondilus
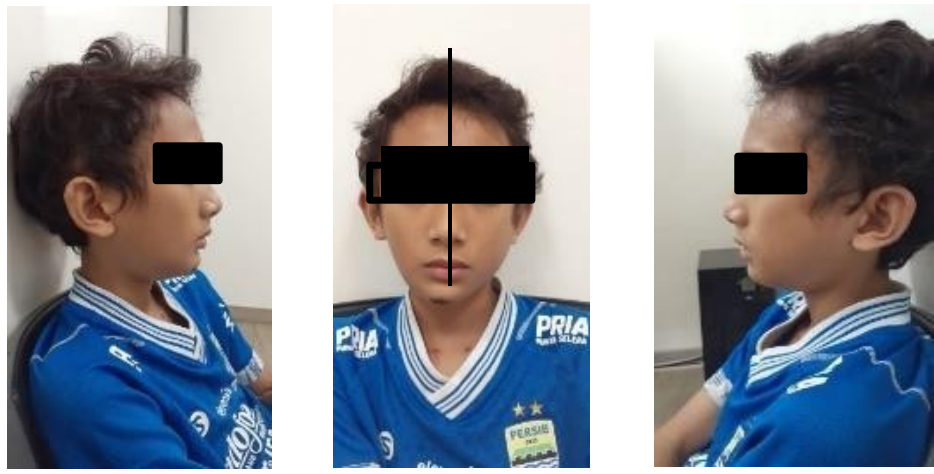

Gambar 1. Pemeriksaan Klinis

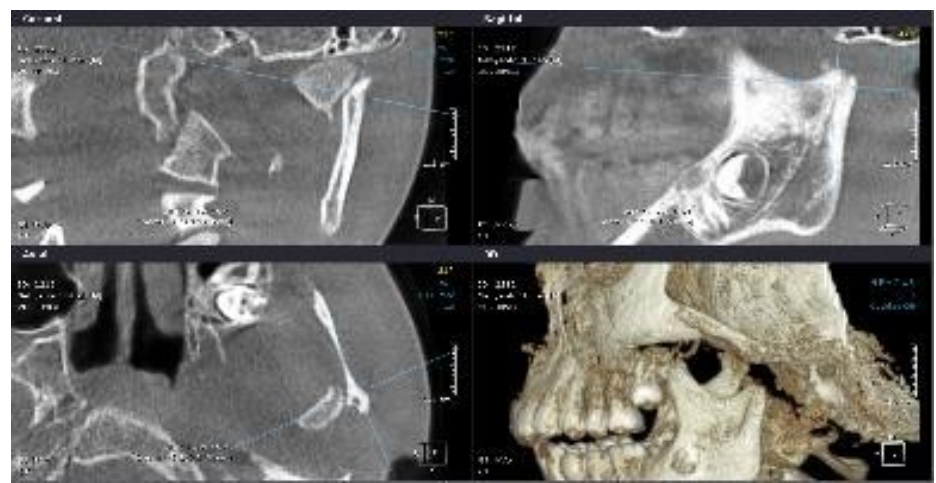

Gambar 2. Gambaran MPR kondilus sinistra
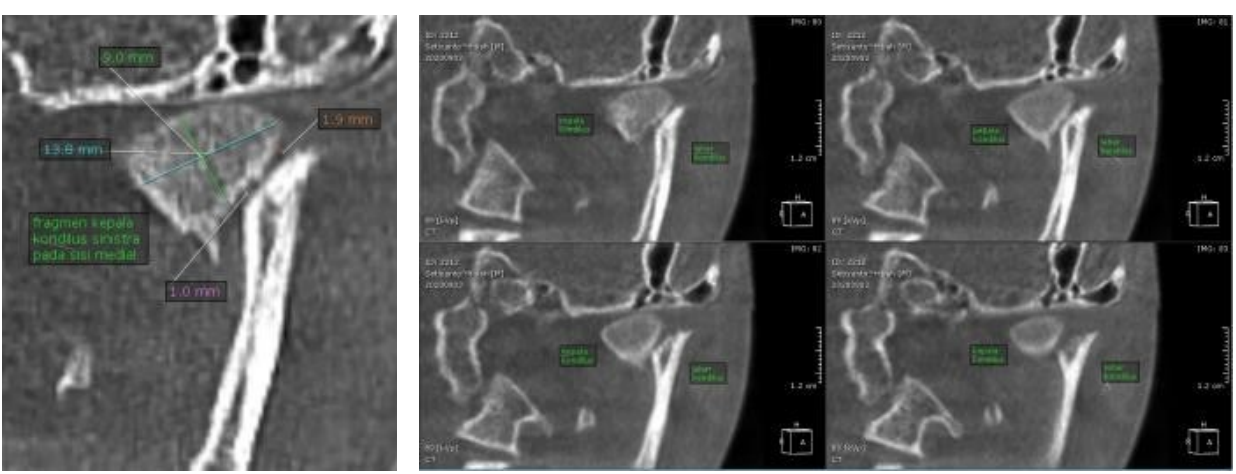

Gambar 3. Gambaran pandangan coronal kondilus sinistra 


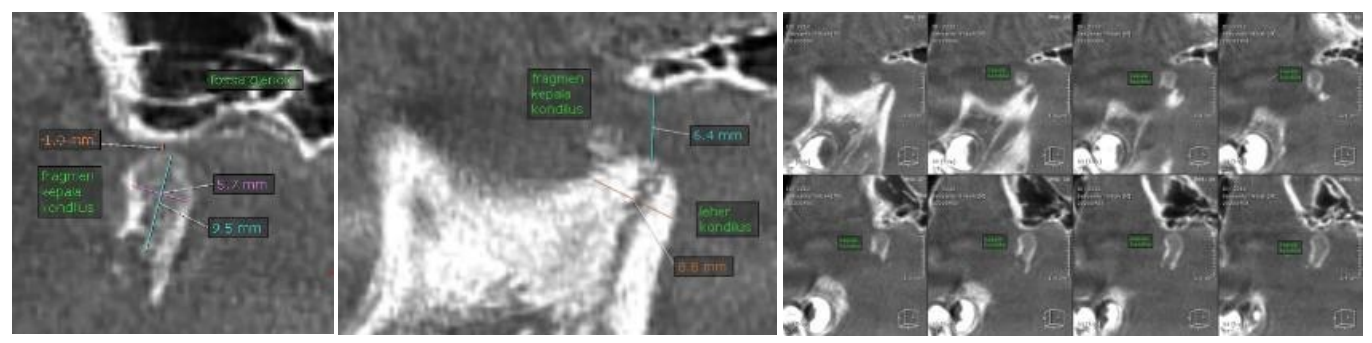

Gambar 4. Gambaran pandangan sagital kondilus sinistra
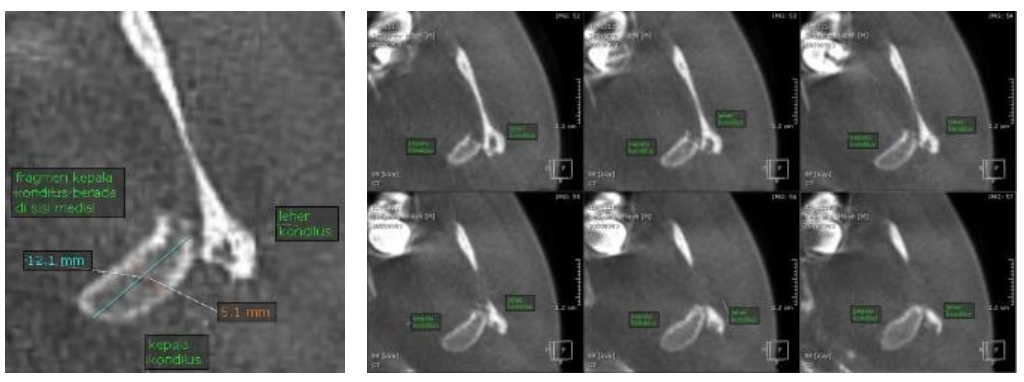

Gambar 5. Gambaran pandangan axial kondilus sinistra

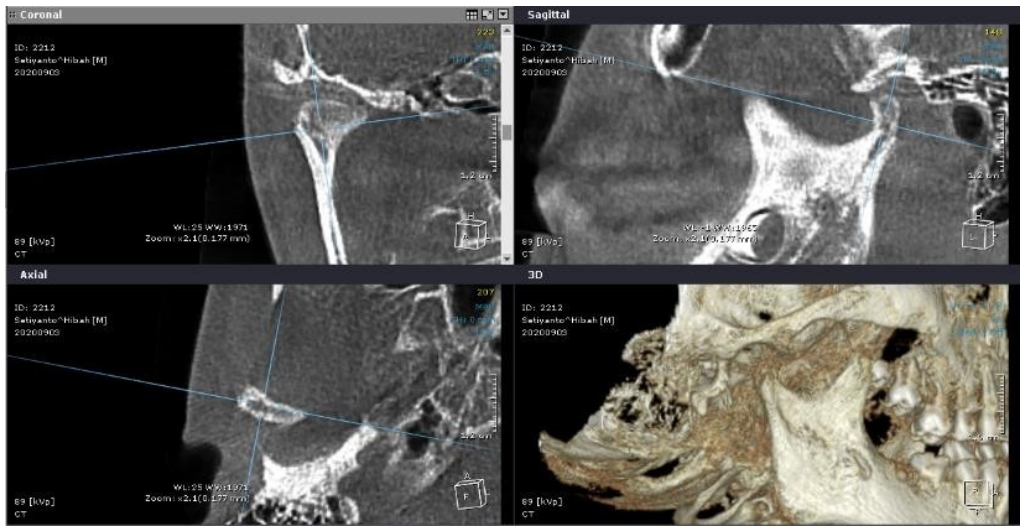

Gambar 6. Gambaran MPR kondilus dextra
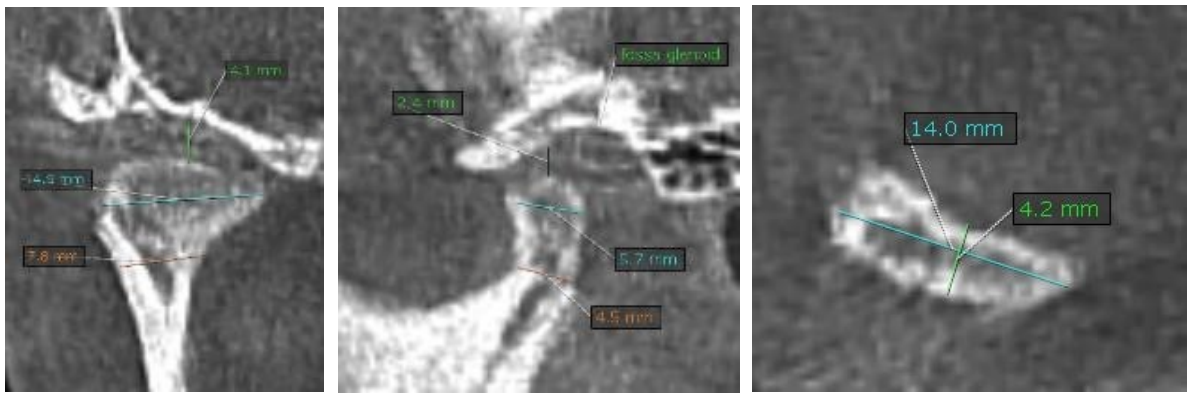

Gambar 7. Gambaran potongan corona, sagittal, axial kondilus dextra
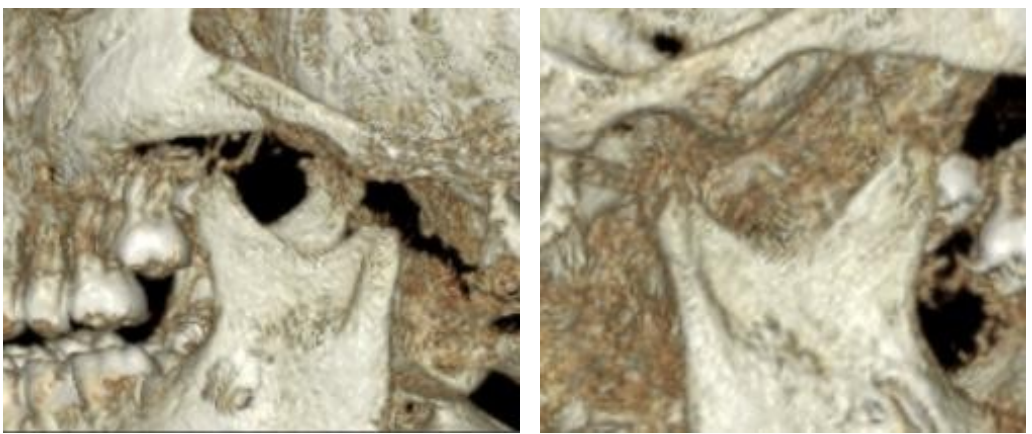

Gambar 8. Gambaran 3D kondilus dextra dan sinistra 


\section{DISKUSI}

Pasien ini mengalami pembengkakan pada daerah telinga dan pipi diikuti nyeri pada buka mulut yang menunjukkan gejala terjadinya gangguan sendi temporomandibular pasca trauma yang disebabkan fraktur leher kondilus. Daerah tulang mandibular yang paling sering terjadi fraktur yaitu daerah kondilus-subkondilus, angulus mandibular, simfisis parasimsifis dan lainnya. ${ }^{7}$ Daerah leher kondilus merupakan daerah yang paling lemah karena ukurannya yang kecil, bentuk anatomi dan letaknya yang berada pada ujung superior tulang mandibula, serta memiliki banyak trabekula dimana bila ada tekanan di sympisis maka akan menerima tekanan secara tidak langsung dan dapat terjadi fraktur. Fraktur ini dapat terjadi bilateral ataupun unilateral, biasanya benturan pada badan mandibular secara lateral dapat menyebabkan fraktur kondilus pada sisi kontaraletralnya. 8

Fraktur kepala kondilus memiliki bermacam tanda dan gejala yang bervariasi, antara lain adanya krepitasi, spasme otot, dan gerakan interfragmen yang menyebabkan terjadinya gangguan fungsional yang ditandai keterbatasan gerak mandibula. Gejala gangguan sendi temporomandibular dapat terjadi akibat fraktur kepala kondilus. Keluhan gangguan pada sendi temporomandibular memerlukan pemeriksaan klinis serta pemeriksaan radiologis yang tepat. ${ }^{10,11}$ Perawatan pada fraktur leher kondilus diutamakan untuk mengembalikan fungsi pengunyahan.

Fraktur leher kondilus memerlukan anamnesa, pemeriksaan klinis serta pemeriksaan penunjang (pemeriksaan radiologis) yang tepat untuk menegakkan diagnosa. Pemeriksaan radiologis yang biasa dipakai untuk melihat fraktur kepala kondilus adalah panoramic atau oblique lateral, posteroanterior (PA) untuk fraktur leher rendah, dan Reverse Towne's untuk fraktur leher tinggi. Fraktur kepala kondilus biasanya berbentuk horizontal, vertical, atau tipe comparative. Gambaran dari fraktur dapat berupa garis radiolusen diantara fragmen tulang apabila terpisah, dapat berupa garis radiopak apabila saling berimpit satu sama lain, dan dapat menyebabkan celah (step) pada batas bawah fragmen tulang. ${ }^{11,12}$

Namun, garis fraktur pada leher kondilus dapat bervariasi dan dapat disertai dislokasi pada leher kondilus. Apabila fragmen tulang overlap, maka akan tampak area yang lebih radiopak dibandingkan dengan garis radiolusen. Pada beberapa kasus pemeriksaan $\mathrm{CBCT}$ lebih diutamakan untuk mengevaluasi fraktur kondilus karena tidak terdapat superimposisi dari struktur stuktur TMJ. Perbedaan gambaran dua dimensi dan tiga dimensi sangat berguna untuk mengetahui letak fragmen fraktur secara akurat. Namun, apabila tidak terdapat pemeriksaan CBCT, maka dapat melakukan beberapa foto radiografi konvensional dari lateral, frontal melalui beberapa sudut untuk mendeteksi letak fraktur. ${ }^{13-15}$ Interpretasi pada pemeriksaan CBCT mencakup bentuk kondilus dan kondisi dari permukaan artikular, kondisi fossa glenoid dan eminensia, serta kondisi penyakit lain yang dapat disebabkan oleh kepala kondilus. ${ }^{7}$

\section{SIMPULAN}

CBCT dapat melihat letak fragmen pada fraktur serta perubahan ukuran dan arah posisi yang terjadi, sedangkan radiografi konvensional sangat sulit untuk melihat kondisi tersebut

\section{DAFTAR PUSTAKA}

1. Indonesia BPS. Statistik Trasportasi 2017.

2. Chief of Traffic Corps Indonesian National Police. Traffic Corps in Number 2013. 2014;1-41.

3. Kemenkes RI. Laporan Nasional Riset Kesehatan Dasar. Kementerian Kesehat RI. 2018;1-582.

4. Mock C, Cherian MN. The global burden of musculoskeletal injuries: Challenges and solutions. Clin Orthop Relat Res. 2008;466(10):2306-16.

5. Astuti R, Putri D. Angka Kejadian Fraktur Mandibula berdasarkan Lokasi Anatomis di RSUD Arifin Achmad Provinsi Riau periode Januari 2011 - Desember 2013. Jom Fk. 2015;1 (2):1-14

6. Herawati H. Karakteristik Dan Penyebab Kecelakaan Lalu Lintas Di Indonesia Tahun 2012. War Penelit Perhub. 2019;26(3):133.

7. Whaites E, Drage N. Essentials of Dental Radiography and Radiology edition fifth. Vol. 53, Journal of Chemical Information and Modeling. 2013. 1689-1699 p.

8. Tanti I, Susanti L. Penatalaksanaan Keterbatasan Gerak Mandibula Akibat Fraktur Kondilus Dengan Splin Reposis (Laporan Kasus). IJD. 2006;

9. Nazarina, Bahri TS. Status Fungsional Paska Orif Fraktur Ekstermitas. JiM FKep [Internet]. 2018;IV(3):1-13. Available from: http://dx.doi.org/10.1186/

10. Wright EF, North SL. Management and Treatment of Temporomandibular Disorders: A Clinical Perspective. J Man Manip Ther. 2009;17(4):247-54.

11. Tamimi D, Kocasarac HD, Mardini S, Wenger KH, Zumbrun SD, Rosas M, et al. HHS Public Access. PLoS One [Internet]. 2020 May 1 [cited 2020 Nov 15];9(1):1-13. Available from: http://link.springer.com/10.1007/978-1-62703-989-5

12. Textbook of Basic Oral Radiology.pdf.

13. White SC, Pharoah MJ. Oral Radiology Principles and Interpretation edition 7

14. Sirin Y, Guven K, Horasan S, Sencan S. Diagnostic accuracy of cone beam computed tomography and conventional multislice spiral tomography in sheep mandibular condyle fractures. Dentomaxillofacial Radiol. 2010;39(6):336-42.

15. Naeem A, Gemal H, Reed D. Imaging in traumatic mandibular fractures. Quant Imaging Med Surg. 2017;7(4):469-79. 